\title{
Optimisation of microalgal starch formation for the biochemical production of biobutanol
}

DOI:

10.1016/B978-0-444-63965-3.50485-2

\section{Document Version}

Accepted author manuscript

Link to publication record in Manchester Research Explorer

\section{Citation for published version (APA):}

Figueroa Torres, G., Pittman, J., \& Theodoropoulos, C. (2017). Optimisation of microalgal starch formation for the biochemical production of biobutanol. In European Symposium on Computer-Aided Process Engineering Elsevier BV. https://doi.org/10.1016/B978-0-444-63965-3.50485-2

\section{Published in:}

European Symposium on Computer-Aided Process Engineering

\section{Citing this paper}

Please note that where the full-text provided on Manchester Research Explorer is the Author Accepted Manuscript or Proof version this may differ from the final Published version. If citing, it is advised that you check and use the publisher's definitive version.

\section{General rights}

Copyright and moral rights for the publications made accessible in the Research Explorer are retained by the authors and/or other copyright owners and it is a condition of accessing publications that users recognise and abide by the legal requirements associated with these rights.

\section{Takedown policy}

If you believe that this document breaches copyright please refer to the University of Manchester's Takedown Procedures [http://man.ac.uk/04Y6Bo] or contact uml.scholarlycommunications@manchester.ac.uk providing relevant details, so we can investigate your claim.

\section{OPEN ACCESS}


Antonio Espuña, Moisès Graells and Luis Puigjaner (Editors), Proceedings of the $27^{\text {th }}$ European Symposium on Computer Aided Process Engineering - ESCAPE 27

October $1^{\text {st }}-5^{\text {th }}, 2017$, Barcelona, Spain (C) 2017 Elsevier B.V. All rights reserved.

\title{
Optimisation of microalgal starch formation for the biochemical production of biobutanol
}

\author{
Gonzalo M. Figueroa-Torres ${ }^{\mathrm{a}}$, Jon K. Pittman ${ }^{\mathrm{b}}$, and Constantinos \\ Theodoropoulos ${ }^{\mathrm{a}, *}$ \\ ${ }^{a}$ School of Chemical Engineering and Analytical Science, Biochemical and Bioprocess \\ Engineering Group, The University of Manchester, Manchester M13 9PL, UK \\ ${ }^{b}$ School of Earth and Environmental Sciences, The University of Manchester, \\ Manchester M13 9PL, UK \\ *k.theodoropoulosl@manchester.ac.uk
}

\begin{abstract}
The current global energy demands have led to an overuse of petroleum resources. In consequence, biofuels have emerged as a suitable and renewable replacement for fossil fuels. A potential replacement for gasoline is biobutanol due to its high heat of combustion, among several other properties (Abdehagh et al., 2014). Biobutanol is produced through $\mathrm{ABE}$ fermentation, a renowned microbial process. An efficient feedstock selection, however, is still necessary to overcome current production challenges (Kumar and Gayen, 2011). Although microalgal biomass has largely been examined as a biodiesel feedstock due to its ability to accumulate oil bodies (Markou et al., 2012), only recently has it been considered a promising substrate for ABE fermentation because its structure contains starch, a polymeric carbohydrate. Simple microalgal cultivation strategies such as nitrogen and phosphorus limitation have been shown to further enhance starch contents (Markou et al., 2012), but such strategies must be effectively implemented to reduce the expected trade-off in growth. Kinetic models capable of predicting cell dynamics during cultivation represent a robust tool for establishing optimized strategies. Nevertheless, most modelling approaches have been constructed under a single-nutrient basis and/or are only able to predict lipid formation. Thus, this work aims to develop a novel predictive multi-parameter kinetic model for the optimization of starch formation during microalgae cultivation. The algal growth rate is co-limited by nitrogen, phosphorus, and the carbon source, and follows a compartmentalized structure considering three intracellular pools: active biomass, starch, and lipids. The model was fitted and successfully validated against experimental datasets generated from lab-scale cultures of Chlamydomonas reinhardtii CCAP 11/32C grown mixotrophically under various nutrient concentrations. Fitting of the model parameters was carried out through an in-house developed optimization algorithm linking stochastic and deterministic methods avoiding getting trapped in local optima. The predictive performance of the model is exploited by establishing the optimal conditions for maximum starch formation.
\end{abstract}

Keywords: microalgae; chlamydomonas; kinetic modelling; biofuels.

\section{Introduction}

Global warming and crude oil depletion have shifted research and industry attention to the area of biofuels and their development. The current sugar-based biofuel market has been dominated by bioethanol, but a higher energy content and compatibility with 
existing infrastructure make biobutanol a more suitable candidate for the energy sector (Kumar and Gayen, 2011). Biobutanol is biochemically produced by the ABE (Acetone-Butanol-Ethanol) fermentation, a microbial process whereby Clostridia species metabolise carbohydrates into fermentation solvents. Although food-based and lignocellulosic feedstocks have been commonly studied for their viability as fermentation substrates, these sugar-rich compounds create challenges due to their competition with food destined for human use and arable land. Recently, microalgae have been considered as a suitable ABE fermentation substrate due to their ability to accumulate starch. Nutrient-limited strategies, such as nitrogen and phosphorus deprivation, have been successfully employed to further increase starch accumulation in microalgal cells, but a simultaneous trade-off in biomass production affects overall productivity (Markou et al., 2012). Optimisation of the microalgal cultivation stage is necessary to establish the optimal initial nutrient concentrations for the formation of starch. Thus, in this work, an integrated experimental and computational study was undertaken to develop a multi-parameter kinetic model for the prediction of starch formation in response to nitrogen, phosphorus, and acetate (carbon) concentrations.

\section{Materials and Methods}

\subsection{Strain and lab-scale cultivation}

Lab-scale experiments were carried out with the wild-type strain Chlamydomonas reinhardtii CCAP 11/32c, grown mixotrophically in Tris-Acetate-Phosphate (TAP) medium. In order to evaluate nutrient-limitation and calibrate the proposed model, six different cultures were grown under various nitrogen $\left(0.3543-0.3824 \mathrm{gN} \mathrm{L}^{-1}\right)$, phosphorus $\left(0.01-0.1 \mathrm{gPO}_{4} \mathrm{~L}^{-1}\right)$, and acetate $\left(0.42-0.84 \mathrm{gC} \mathrm{L}^{-1}\right)$ concentrations. Culture vessels contained $500 \mathrm{~mL}$ of medium and $1 \mathrm{~mL}$ of algal inoculum, and were kept at $25{ }^{\circ} \mathrm{C}$ and $150 \mathrm{rpm}$ while providing constant illumination of $125 \mu_{\mathrm{mol} \mathrm{m}}^{-2} \mathrm{~s}^{-1}$ in a light/dark cycle of 16/8 hours. Samples of the biomass and residual medium were taken at regular intervals throughout the cultivation period until cells attained the stationary phase.

\subsection{Analytical methods}

The cell dry weight was determined gravimetrically by drying the wet biomass for $24 \mathrm{~h}$ at $70{ }^{\circ} \mathrm{C}$. Starch concentration was measured by means of a colorimetric Total Starch Kit as per the method supplied by Megazyme International, Ireland. Lipid concentration was quantified by solvent extraction in a SOXTEC Unit 1043, where oil extraction was carried out for $2 \mathrm{~h}$ using hexane at $160{ }^{\circ} \mathrm{C}$. Extraction was then followed by rinsing and evaporating stages of $20 \mathrm{~min}$ and $30 \mathrm{~min}$, respectively. Extracted oil was then measured gravimetrically. The residual nutrient concentrations were determined as follows: nitrogen was measured in a TOC- $\mathrm{V}_{\mathrm{CSH}} / \mathrm{TNM}-1$, Shimadzu (Total Organic Carbon/ Total Nitrogen); phosphorus was quantified in a Varian Vista MPX ICP-OES at $\lambda=213 \mathrm{~nm}$ (Inductively Coupled Plasma - Optical Emission Spectroscopy); acetic acid was quantified by HPLC (High Pressure Liquid Chromatography) in a Hi-Plex column $(8 \mathrm{~m}, 300 \times 7.7 \mathrm{~mm})$ coupled with a UV detector at $\lambda=210 \mathrm{~nm} . \mathrm{H}_{2} \mathrm{SO}_{4} 5 \mathrm{mM}$ was used as mobile phase at $50{ }^{\circ} \mathrm{C}$ and a flow rate of $0.6 \mathrm{~mL} \mathrm{~min}^{-1}$.

\section{Kinetic Modelling}

The multi-parameter model presented here is based on our previous modelling work (Figueroa-Torres et al., 2016), which was expanded to account for phosphorus-limited 
growth. The model considers the following 9 state variables: Total biomass $\left(X, \mathrm{gC} \mathrm{L}^{-1}\right)$, starch $\left(S, \mathrm{gC} \mathrm{L}^{-1}\right)$, lipids $\left(L, \mathrm{gC} \mathrm{L}^{-1}\right)$, active biomass $\left(x^{*}, \mathrm{gC} \mathrm{L}^{-1}\right)$, nitrogen $\left(N, \mathrm{gN} \mathrm{L}^{-1}\right)$, nitrogen quota $\left(q_{N}, \mathrm{gN} \mathrm{gC}^{-1}\right)$, phosphorus $\left(P, \mathrm{gPO}_{4} \mathrm{~L}^{-1}\right)$, phosphorus quota $\left(q_{P}, \mathrm{gPO}_{4} \mathrm{gC}^{-}\right.$ $\left.{ }^{1}\right)$, and acetate $\left(A, \mathrm{gC} \mathrm{L}^{-1}\right)$. All kinetic parameters are defined and presented in Table 1 . Following the approach of Mairet et al. (2011), total biomass is made up of three carbon-based elements: starch, lipids, and active biomass (i.e. $X=S+L+x^{*}$ ). Starch and lipid dynamics incorporate formation and degradation rates and depend mainly on the internal nitrogen $\left(N_{\text {int }}=q_{N} \cdot X\right)$ and carbon $\left(A_{\text {int }}=A-A_{o}\right)$ concentrations. Accumulation rates for these elements are described by Eq.(1) - Eq.(4).

$\frac{d X}{d t}=\mu \cdot X$

$\frac{d S}{d t}=r_{1} \cdot \frac{N_{\text {int }}^{n_{S}}}{N_{\text {int }}^{n_{S}}+K_{S, S}^{n_{s}}+\left(N_{\text {int }}^{2} / k_{i, S}\right)^{n_{S}}} \cdot \frac{k_{1}}{k_{1}+N / N_{o}} \cdot\left(1+\frac{1}{\mu} \cdot e^{\phi_{S} \cdot A_{\text {int }}}\right) \cdot \mu \cdot x^{*}-\frac{r_{2}}{q_{N}} \cdot X$

$\frac{d L}{d t}=r_{3} \cdot \frac{N_{\text {int }}^{n_{L}}}{N_{\text {int }}^{n_{L}}+K_{s, L}^{n_{L}}+\left(N_{\text {int }}^{2} / k_{i, L}\right)^{n_{L}}} \cdot \frac{k_{2}}{k_{2}+N / N_{o}} \cdot\left(1+\frac{1}{\mu} \cdot e^{\phi_{S} \cdot A_{\text {int }}}\right) \cdot \mu \cdot x^{*}-\frac{r_{4}}{q_{N}} \cdot X$

$\frac{d x^{*}}{d t}=\frac{d X}{d t}-\left(\frac{d S}{d t}+\frac{d L}{d t}\right)$

Here, a new mathematical expression for the algal specific growth rate, $\mu$, was constructed so as to portray mixotrophic microalgal growth under either nitrogen or phosphorus limitation. Mixotrophic conditions are expressed by the sum of the heterotrophic and phototrophic growth rates, $\mu_{H}$ and $\mu_{I}$, both modelled as Haldane functions to account for inhibition. The growth rates limited by nitrogen and phosphorus, $\mu_{N}$ and $\mu_{P}$, are modelled as Droop functions subject to a minimum law as shown in Eq.(5).

$$
\begin{aligned}
& \mu=\mu_{\max } \cdot\left[w_{H} \cdot \mu_{H}(A)+w_{I} \cdot \mu_{I}(I)\right] \cdot \min \left[\mu_{N}\left(q_{N}\right), \mu_{P}\left(q_{P}\right)\right] \\
& \mu=\mu_{\max } \cdot\left(w_{H} \cdot \frac{A}{A+K_{s, A}+A^{2} / k_{i, A}}+w_{I} \cdot \frac{I}{I+K_{s, I}+I^{2} / k_{i, I}}\right) \cdot \min \left(1-\frac{q_{N, 0}}{q_{N}}, 1-\frac{q_{P, 0}}{q_{P}}\right)
\end{aligned}
$$

In Eq. (5), $w_{H}$ and $w_{P}$, are weighing functions accounting for the contribution of the heterotrophic or phototrophic rates to overall growth. Light distribution, I, along the culture vessel (with a depth equivalent to $z, \mathrm{~m}$ ) is described by the Beer-Lambert law:

$$
I=I_{o} \exp (-\sigma X z)
$$

Consumption of acetate, nitrogen, and phosphorus over the cultivation period is described by Eq.(8) - Eq.(10), respectively. 
$\frac{d A}{d t}=-\frac{1}{Y_{X / A}} \cdot \frac{\mu_{H}(A)}{\mu_{H}(A)+\mu_{I}(I)} \cdot \frac{d X}{d t}$

$\frac{d N}{d t}=-\rho_{N} \cdot X=-\bar{\rho}_{N, \max }(X) \cdot \frac{N}{N+K_{s, N}+N^{2} / k_{i, N}} \cdot \frac{A}{A+K_{s, A: N}+A^{2} / k_{i, A: N}} \cdot X$

$\frac{d P}{d t}=-\rho_{P} \cdot X=-\bar{\rho}_{P, \max }(X) \cdot \frac{P}{P+K_{s, P}+P^{2} / k_{i, P}} \cdot \frac{A}{A+K_{s, A: P}+A^{2} / k_{i, A: P}} \cdot X$

The specific uptakes rates of nitrogen and phosphorus, $\rho_{N}$ and $\rho_{P}$, are expressed by inhibited-type kinetics so as to account for the inhibition of growth observed at high nutrient concentrations. Furthermore, since nutrient consumption was found to stop at high cell densities, the maximum uptake rates of nitrogen and phosphorus are both regulated by a decreasing function of total biomass, as shown in Eq.(11) and Eq.(12). In line with experimental observations, the maximum nitrogen uptake is additionally a function of both the initial nitrogen concentration and the phosphorus quota.

$$
\begin{aligned}
& \bar{\rho}_{N, \text { max }}(X)=\rho_{N, \text { max }} \cdot e^{-\phi_{N} X} \cdot \frac{N_{o}^{n}}{N_{o}^{n}+K_{N o}^{n}} \cdot\left(1-\frac{K_{q_{P}}}{q_{P}}\right) \\
& \bar{\rho}_{P, \text { max }}(X)=\rho_{P, \max } \cdot e^{-\phi_{P} X}
\end{aligned}
$$

Finally, the dynamics of the intracellular nitrogen and phosphorus quotas are obtained by differentiation with respect to time, which yields:

$$
\begin{aligned}
& \frac{d q_{N}}{d t}=\rho_{N}-q_{N} \cdot \mu \\
& \frac{d q_{P}}{d t}=\rho_{P}-q_{P} \cdot \mu
\end{aligned}
$$

\section{Results and discussion}

From the six lab-scale batch cultures grown under various N-P-A regimes, four experimental datasets were used to fit model parameters and two were used for validation. The values of each parameter (Table 1) were estimated by minimizing an objective function defined as the sum of squared relative error (Error) between experimental data and model predictions. Minimization was carried out through a stochastic optimization algorithm coupled with a deterministic method as per the methodology of Vlysidis et al., (2011). The results from the preceding method are presented in Figure 1, showing predicted time-profiles of biomass, starch and lipids against their corresponding experimental values only for two different datasets.

Table 1. Kinetic parameters: definitions and corresponding values. 


\begin{tabular}{|c|c|c|c|c|}
\hline Parameter & Value & Units & Parameter & Value \\
\hline Maximum specific growth rate & 0.1106 & $\mathrm{~h}^{-1}$ & $\Phi_{P}$ Uptake regulation coefficient & $29.067 \mathrm{~L} \mathrm{gC}^{-1}$ \\
\hline Minimum nitrogen quota & 0.8767 & $\mathrm{gN} \mathrm{gC}^{-1}$ & $K_{s, P}$ Half-saturation constant $(\mathrm{P})$ & $0.448 \mathrm{gPO}_{4} \mathrm{~L}^{-1}$ \\
\hline Minimum phosphorus quota & 0.0092 & $\mathrm{gPO}_{4} \mathrm{gC}^{-1}$ & $K_{i, N}^{j, 2}$ Inhibition constant $(\mathrm{P})$ & $2.428 \mathrm{gPO}_{4} \mathrm{~L}^{-1}$ \\
\hline Half-saturation constant (A) & 1.7892 & $\mathrm{gC} \mathrm{L}^{-1}$ & $K_{S, A: P}$ Half-saturation constant (A) & $1.269 \mathrm{gC} \mathrm{L}^{-1}$ \\
\hline$k_{i, A} \quad$ Inhibition constant $(\mathrm{A})$ & 0.1097 & $\mathrm{gC} \mathrm{L}^{-1}$ & $k_{i, A: P}$ Inhibition constant (A) & $0.206 \mathrm{gC} \mathrm{L}^{-1}$ \\
\hline$K_{s, I} \quad$ Half-saturation constant (I) & 1.0782 & $\mu \mathrm{mol} \mathrm{m} \mathrm{s}^{-1}$ & $r_{1}$ Rate of starch formation & $0.3841 \mathrm{gC} \mathrm{gC}^{-1}$ \\
\hline$k_{i, I} \quad$ Inhibition constant (I) & 186.5275 & $\mu \mathrm{mol} \mathrm{m} \mathrm{s}^{-1}$ & $r_{2}$ Rate of starch degradation & $0.0025 \mathrm{gN} \mathrm{gC}^{-1} \mathrm{~h}^{-1}$ \\
\hline$Y_{X / A} \quad$ Yield coefficient (A to $\mathrm{X}$ ) & 0.0399 & $\mathrm{gC} \mathrm{gC}^{-1}$ & $r_{3} \quad$ Rate of lipid formation & $0.3908 \mathrm{gC} \mathrm{gC}^{-1}$ \\
\hline Light attenuation coefficient & 0.6499 & $\mathrm{~L} \mathrm{gC}^{-1} \mathrm{~m}^{-1}$ & $r_{4}$ Rate of lipid degradation & $0.0054 \mathrm{gN} \mathrm{gC}^{-1} \mathrm{~h}^{-1}$ \\
\hline$\rho_{N, \max }$ Maximum nitrogen uptake rate & 40.445 & $\mathrm{gN} \mathrm{gC}^{-1} \mathrm{~h}^{-1}$ & $K_{s, S}$ Half-saturation constant & $0.0477 \mathrm{gN} \mathrm{L}^{-1}$ \\
\hline$K_{N o} \quad$ Half-saturation constant (No) & 0.3125 & $\mathrm{gN} \mathrm{L}^{-1}$ & $k_{i, S}$ Inhibition constant & $0.1409 \mathrm{gN} \mathrm{L}^{-1}$ \\
\hline$n \quad$ Shape-controlling parameter & 126.767 & - & $n_{S}$ Shape-controlling parameter & $3.6418-$ \\
\hline$\Phi_{N} \quad$ Uptake regulation coefficient & 137.455 & $\mathrm{~L} \mathrm{gC}^{-1}$ & $k_{l}$ Regulation constant for $\mathrm{R}_{1}$ & $0.0354-$ \\
\hline$K_{q P} \quad$ Minimum $\mathrm{P}$ quota for $\mathrm{N}$ uptake & 0.165 & $\mathrm{gPO}_{4} \mathrm{gC}^{-1}$ & $\Phi_{S}$ Regulation constant for $\mathrm{R}_{1}$ & $0.0000 \mathrm{~L} \mathrm{gC}^{-1}$ \\
\hline$K_{S, N} \quad$ Half-saturation constant $(\mathrm{N})$ & 0.163 & $\mathrm{gN} \mathrm{L}^{-1}$ & $K_{s, L}$ Half-saturation constant & $0.0481 \mathrm{gN} \mathrm{L}^{-1}$ \\
\hline$k_{i, N} \quad$ Inhibition constant $(\mathrm{N})$ & 0.113 & $\mathrm{gN} \mathrm{L}^{-1}$ & $k_{i, L}$ Inhibition constant & $0.0275 \mathrm{gN} \mathrm{L}^{-1}$ \\
\hline$K_{S, A: N}$ Half-saturation constant (A) & 1.004 & $\mathrm{gC} \mathrm{L}^{-1}$ & $n_{L} \quad$ Shape-controlling parameter & $1.3321-$ \\
\hline$K_{i, A: N}$ Inhibition constant (A) & 1.098 & $\mathrm{gC} \mathrm{L}^{-1}$ & $k_{2}$ Regulation constant for $\mathrm{R}_{2}$ & $0.2434-$ \\
\hline$\rho_{P \max }$ Maximum $\mathrm{PO}_{4}$ uptake rate & 13.997 & $\mathrm{gPO}_{4} \mathrm{gC}^{-1} \mathrm{~h}^{-1}$ & $\Phi_{L}$ Regulation constant for $\mathrm{R}_{2}$ & 1.0E-05 $\mathrm{L} \mathrm{gC}^{-1}$ \\
\hline
\end{tabular}

As seen in Figure 1, a good level of agreement between predictions and experimental data was achieved (Error $=1.956$ ), indicating the model's potential as a robust tool in the establishment of optimized cultivation strategies. Given that microalgal starch is a potential substrate for biobutanol production, a cultivation strategy for optimal starch formation was established in terms of the initial set of nitrogen, phosphorus, and acetate (N-P-A) concentrations.
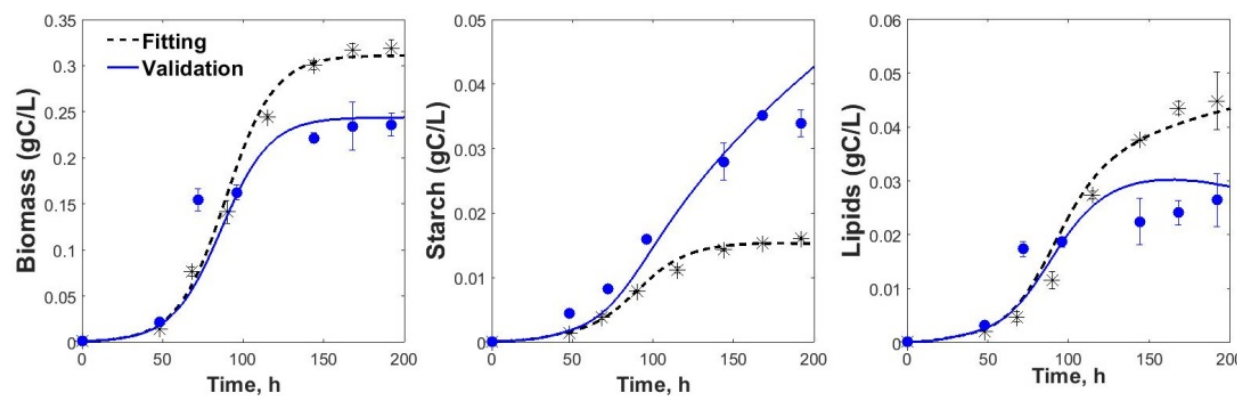

Figure 1. Predicted time-profile for biomass, starch, and lipids, against experimental data. Fitting: culture grown in TAP $\left(0.3824 \mathrm{gN} \mathrm{L}^{-1}, 0.1 \mathrm{gPO}_{4} \mathrm{~L}^{-1}\right.$, and $\left.1.05 \mathrm{gC} \mathrm{L}^{-1}\right)$; Validation: culture grown in A-enrichment and P-limitation $\left(0.3824 \mathrm{gN} \mathrm{L}^{-1}, 0.01 \mathrm{gPO}_{4}\right.$ $\mathrm{L}^{-1}$, and $\left.1.26 \mathrm{gC} \mathrm{L}^{-1}\right)$. Error bars are the standard deviation from two replicates.

The optimal N-P-A set was identified in a ternary diagram for starch formation, which was constructed from the predictions generated by the validated model at a cultivation time of $190 \mathrm{~h}$ (period of stationary phase). The resulting diagram is presented in Figure 2 , showing that a starch concentration of up to $0.06 \mathrm{gC} \mathrm{L}^{-1}$ could be obtained by $C$. reinhardtii cultures if grown under the encircled N-P-A concentration sets. When compared with the starch concentration attained by cultures grown in standard TAP medium $\left(0.016 \mathrm{gC} \mathrm{L}^{-1}\right)$, this predicted increase in starch formation translates into a larger availability of the carbohydrate pool that will be ultimately required by Clostridial species to produce biobutanol. 


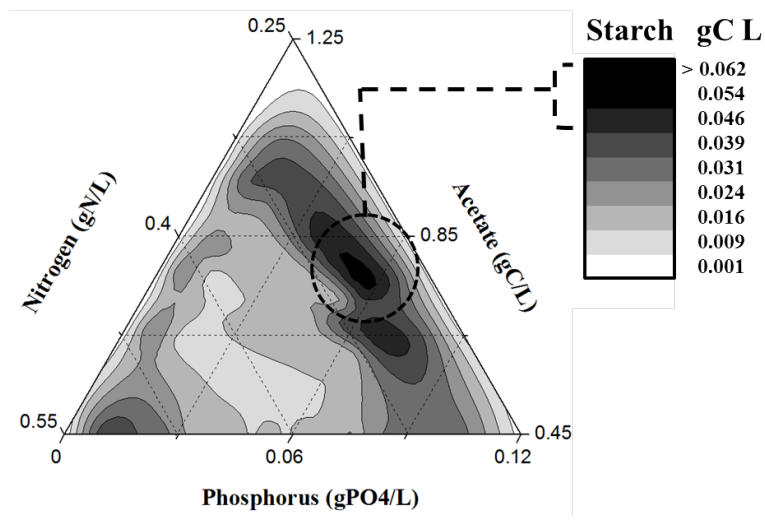

Figure 2. Ternary diagram displaying predicted formation of microalgal starch $(\mathrm{t}=$ $190 \mathrm{~h}$ ) with respect to initial nitrogen, phosphorus, and acetate concentrations. Circled area corresponds to optimal N-P-A sets for starch accumulation.

\section{Conclusions}

A multi-parameter kinetic model responsive to nitrogen, phosphorus, and acetate concentrations was developed to predict starch formation during microalgae cultivation. Parameter fitting was carried out by means of a global optimisation algorithm avoiding getting trapped in local optima. Model predictions, obtained with the set of fitted parameters, were accurately validated with experimental data. Optimal conditions for microalgal starch formation were additionally established to identify improved microalgae-to-biobutanol production routes.

\section{References}

N. Abdehagh, F.H. Tezel, J. Thibault, 2014. Separation techniques in butanol production: Challenges and developments. Biomass and Bioenergy 60, 222-246.

G. Figueroa-Torres, J. Pittman, C. Theodoropoulos, 2016. Modelling of Starch Production by Microalgal Biomass under Multi-nutrient Limitation, in: Engineering, Z.K. and M.B.B.T.-C.A.C. (Ed.), 26th European Symposium on Computer Aided Process Engineering. Elsevier, pp. 2133-2138.

M. Kumar, K. Gayen, 2011. Developments in biobutanol production: New insights. Appl. Energy 88, 1999-2012.

F. Mairet, O. Bernard, P. Masci, T. Lacour, A. Sciandra, 2011. Modelling neutral lipid production by the microalga Isochrysis aff. galbana under nitrogen limitation. Bioresour. Technol. 102, 142-9.

G. Markou, I. Angelidaki, D. Georgakakis, 2012. Microalgal carbohydrates: an overview of the factors influencing carbohydrates production, and of main bioconversion technologies for production of biofuels. Appl. Microbiol. Biotechnol. 96, 631-645.

A. Vlysidis, M. Binns, C. Webb, C. Theodoropoulos, 2011. Glycerol utilisation for the production of chemicals: Conversion to succinic acid, a combined experimental and computational study. Biochem. Eng. J. 58-59, 1-11. 